Synthesis of Natural

Products and

Potential Drugs

\title{
Synthesis of LY2623091
}
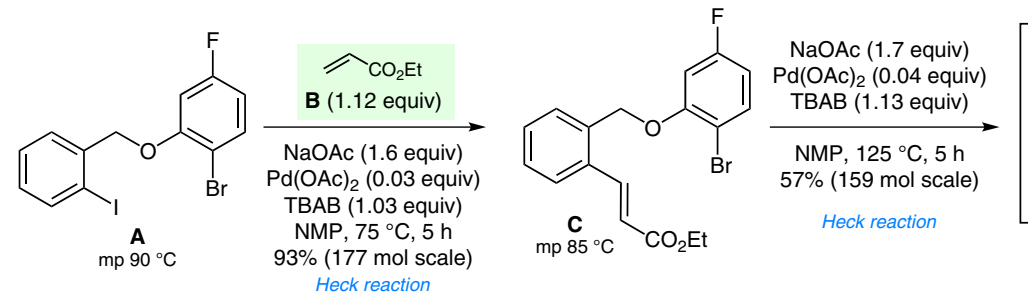

Heck reactic
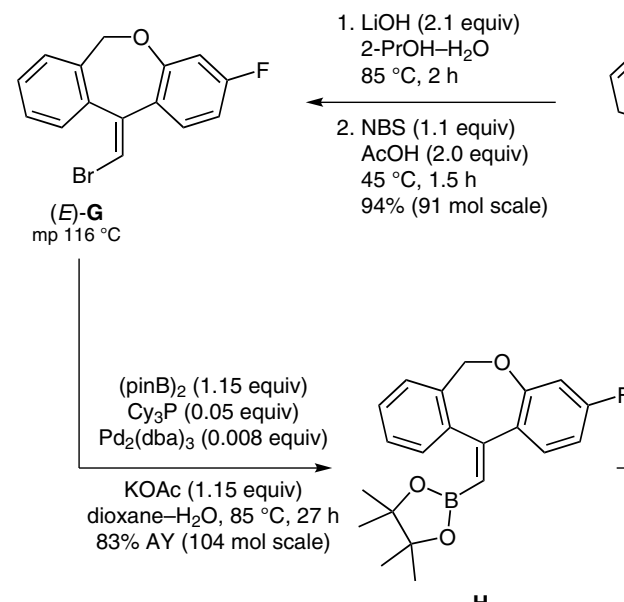

H

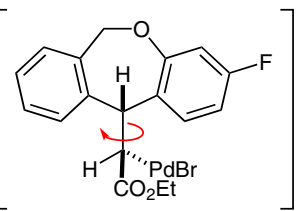

D
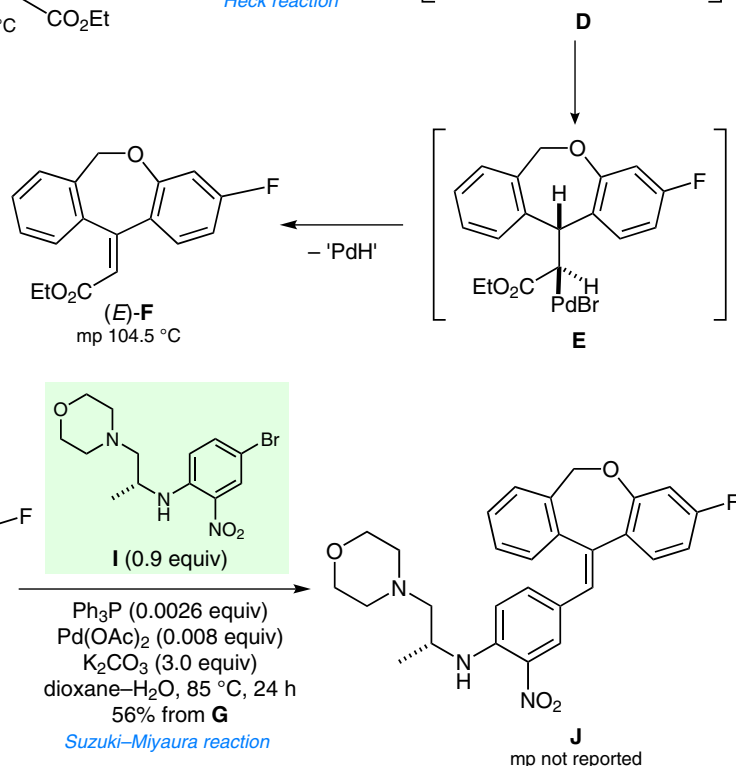

mp not reported
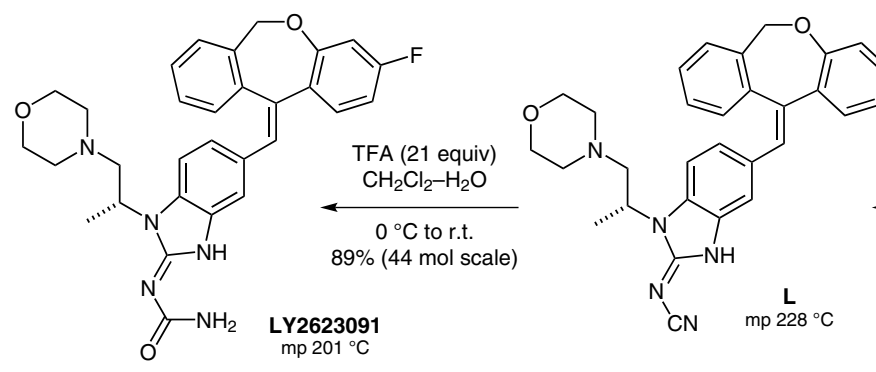

1. $\mathrm{H}_{2}(50-55 \mathrm{psi}), 5 \% \mathrm{Pt} / \mathrm{C}$

$\mathrm{Et}_{3} \mathrm{~N}$ (0.09 equiv)

EtOAc, $45^{\circ} \mathrm{C}, 24 \mathrm{~h}$

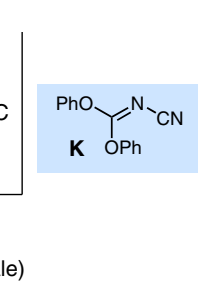

2. $\mathbf{K}$ (1.05 equiv)

EtOAc, $\Delta, 18 \mathrm{~h}$

$80 \%$ from $\mathbf{J}$ ( $57 \mathrm{~mol}$ scale)

Significance: LY2623091 is a mineralocorticoid receptor antagonist that was of interest for the treatment of resistant hypertension. The kilogramscale synthesis depicted features two sequential Heck reactions to construct the $(E)$-dihydrodibenzo[b,e]oxepine ring system. Note the clean retention of stereochemistry in the conversion of $(E)-\mathbf{F}$ into bromoalkene $(E)$-G.
Comment: An investigation of the conversion of $\mathbf{A}$ into $(E)-\mathbf{F}$ through a one-pot, double Heck reaction revealed that the first Heck reaction $(\mathbf{A} \rightarrow \mathbf{C})$ was fast and occurred at $60{ }^{\circ} \mathrm{C}$ whereas the second Heck reaction $[\mathbf{C} \rightarrow(E)-\mathbf{F}]$ required a much higher temperature $\left(145^{\circ} \mathrm{C}\right)$ owing to iodide acting as a catalyst poison. Better yields and stereoselectivity were obtained in the two-pot process shown.

SYNFACTS Contributors: Philip Kocienski 